\title{
Acessibilidade e mobilidade espaciais da população na Região Metropolitana de Belo Horizonte: análise com base no censo demográfico de 2010
}

\author{
Spatial accessibility and mobility of the population \\ in the Metropolitan Region of Belo Horizonte: \\ analysis based on the 2010 demographic census
}

Carlos Lobo Leandro Cardoso

David J. A. V. Magalhães

\section{Resumo}

A Região Metropolitana de Belo Horizonte, a exemplo de outras grandes metrópoles nacionais, apresenta condições inadequadas de deslocamento de pessoas e mercadorias. Somadas às precariedades dos transportes públicos coletivos e aos elevados índices de acidentes de trânsito, têm sido agravados os problemas referentes a congestionamentos e poluição, fatores que impactam negativamente a vida das pessoas e as diversas atividades sociais e econômicas. Torna-se relevante, nesse aspecto, aprofundar nas investigações acerca das condições de acessibilidade e mobilidade espaciais nesses aglomerados urbanos. Este artigo tem por objetivo a proposição e a análise de indicadores de acessibilidade e de mobilidade espaciais da população nos fluxos intermunicipais na RMBH, tendo como base os valores de distância, tempo e velocidade média dos deslocamentos identificados na base amostral do censo demográfico de 2010.

Palavras-chave: acessibilidade; mobilidade; regiões metropolitanas; censo demográfico; Belo Horizonte.

\begin{abstract}
The Metropolitan Region of Belo Horizonte, like others in Brazil, offers inadequate conditions for the movement of people and commodities. In addition to the precariousness of the public transportation system and the high rates of traffic accidents, one can observe a gradual worsening of problems related to traffic jams and pollution, factors that negatively impact the quality of urban life and economy. Therefore, it is relevant to carry out a diagnosis of the conditions of spatial accessibility and mobility in these urban areas. This article proposes and analyzes indicators of spatial accessibility and mobility of people among the cities located within the metropolitan region of Belo Horizonte (Southeastern Brazil), based on the values of distance, time and average speed of movements identified in the Brazilian census sample of 2010.
\end{abstract}

Keywords: accessibility; mobility; metropolitan regions; demographic census; Belo Horizonte. 


\section{Introdução}

A mobilidade e a acessibilidade urbanas são atributos das cidades e representam duas das mais importantes vantagens comparativas propiciadas pelo espaço urbano, em face de suas alternativas em termos de localização de atividades e serviços. Nesse contexto, as principais metrópoles nacionais possibilitam facilidade de contatos que colocam os cidadãos metropolitanos diante de oportunidades de transações, comunicação social e consumo, não raro indisponíveis em espacialidades urbanas de menor porte e/ou mais afastados das áreas mais desenvolvidas economicamente, fato que potencializa a sua atratividade.

Com efeito, os serviços de transporte e trânsito, em particular, afiguram-se como um dos meios de consumo coletivo que apresentam problemas mais visíveis e sentidos pela população, independentemente da classe social (embora os mais pobres sejam notoriamente mais prejudicados), uma vez que esses sistemas interagem diretamente com a estruturação do espaço. Fruto de um crescimento urbano acelerado, pautado principalmente pela adoção de um modelo de planejamento econômico voltado para o incentivo à industrialização, tais condições, associadas às precariedades dos transportes públicos coletivos e, principalmente, ao incremento da utilização de modalidades de transporte individual, têm contribuído para 0 avanço de problemas referentes aos elevados índices de acidentes de trânsito, ao aumento dos congestionamentos viários e dos níveis de poluição, fatores que acarretam processos de vulnerabilidade social, uma vez que impactam negativamente a vida das pessoas e as diversas atividades sociais e econômicas, indispensáveis à manutenção da dinâmica urbana. Ademais, pela falta de alternativas de acessibilidade em outras direções e pela intensa centralização ainda presente em algumas das principais regiões metropolitanas brasileiras, os transportes podem agravar convergências para polos já saturados, elevando custos econômicos e sociais da cidade e obrigando a população residente na periferia metropolitana a percorrer grandes distâncias para usufruir os serviços que somente as áreas centrais fornecem (Hicks, 1979)، contribuindo, em última análise, para o declínio na qualidade de vida urbana.

A Região Metropolitana de Belo Horizonte (RMBH) afigura-se como um exemplo esclarecedor dessas afirmações, uma vez que a Capital do estado de Minas Gerais recebe, diariamente, a partir de dados censitários, elevados contingentes de trabalhadores que residem nos municípios da periferia metropolitana, dado o seu grau de polarização de oportunidades de trabalho e serviços. Consequentemente, tanto o sistema de transporte público (inter e intra) municipal (majoritariamente realizado por ônibus) quanto o sistema de circulação são ainda mais onerados por uma crescente demanda por deslocamentos motivados pelo trabalho, situação também compartilhada por outras grandes cidades brasileiras.

Nesse sentido, este artigo tem como objetivo principal a proposição e a análise de indicadores de acessibilidade e de mobilidade espaciais da população nos fluxos intermunicipais na RMBH, tendo como base os valores de distância, tempo e velocidade média dos deslocamentos identificados no questionário amostral do censo demográfico de 2010, realizado pelo Instituto Brasileiro de Geografia 
e Estatística (IBGE). Para tanto, foram selecionados os deslocamentos motivados pelo trabalho e originados nos municípios que integram a periferia da RMBH com destino a Belo Horizonte. A partir dessa base de dados foi possível identificar os fluxos entre as unidades espaciais denominadas Áreas de Ponderação (Areap), o que permitiu não somente obter sinais acerca da (in)eficiência das condições de deslocamento intermunicipal na RMBH, também associadas à confirmação da elevada centralidade metropolitana da capital mineira em relação ao restante da $\mathrm{RMBH}$, mas ainda obter uma análise comparativa das condições de acessibilidade e mobilidade nas nove principais regiões metropolitanas do país. Importa ressaltar que a metodologia de análise proposta neste artigo pode ser útil na elaboração de novos indicadores de acessibilidade e mobilidade urbanas, úteis às discussões públicas e à elaboração e proposição de políticas de transporte e trânsito urbanos.

Importa ressaltar que tais investigações poderiam ser realizadas, até com maior precisão, utilizando-se dados da Pesquisa Domiciliar de Origem e Destino (OD), a qual fornece informações diversas sobre os municípios que integram a RMBH, como por exemplo, aspectos socioeconômicos e demográficos relativos ao indivíduo e ao domicílio de moradia, o tempo gasto entre a moradia e o local de trabalho, 0 modo de transporte utilizado, entre outros. Para o caso belo-horizontino, entretanto, há uma carência de dados atualizados sobre mobilidade e acessibilidade espaciais, tendo em conta que a pesquisa OD mais recente realizada na RMBH data de 2002. Com periodicidade decenal, a Pesquisa OD de 2012 tem previsão de publicação somente no segundo semestre de 2013.
Nesse contexto, a proposta deste trabalho ganha ainda maior relevância por sugerir o aproveitamento do censo demográfico como outra fonte consistente de dados que, pela primeira vez em toda a sua série histórica, inseriu no seu questionário informações sobre mobilidade e acessibilidade (ainda que menos detalhadas que as pesquisas OD). Ademais, a metodologia aqui empregada pode também servir de referência para estudiosos que necessitem empreender investigações sobre municípios que não realizam pesquisas OD periodicamente.

\section{Breves notas sobre a acessibilidade e a mobilidade urbanas em Belo Horizonte: aspectos conceituais e metodológicos}

0 conceito de acessibilidade é objeto de recorrentes controvérsias e discussões, sobretudo por ser comumente utilizado por uma significativa gama de ramos do conhecimento (Lobo, Cardoso e Matos, 2010). 0 amplo emprego do termo em várias circunstâncias conduz a equívocos conceituais, o que o leva a certa descaracterização conceptual. Não raro, os termos acessibilidade e mobilidade são considerados sinônimos. Jones (1981), por exemplo, relaciona o conceito de acessibilidade a oportunidade que um indivíduo possui para participar de uma atividade em um dado local. Essa po- tencialidade disponibilizada pelo sistema de transporte e pelo uso do solo permitiria que diferentes tipos de pessoas desenvolvessem suas atividades. Ainda de acordo com o autor, o termo 
mobilidade refere-se à capacidade de um indivíduo de se deslocar espacialmente e envolve dois componentes. 0 primeiro irá depender do desempenho do sistema de transporte, revelada pela sua capacidade de interligar locais distintos. Já o segundo depende das características próprias do indivíduo, associadas ao seu grau de inserção perante o sistema de transporte, e das suas necessidades. Noutros termos, acessibilidade associa-se à capacidade de alcançar um determinado lugar, sendo comumente mensurada pelo atributo tempo de viagem, enquanto que mobilidade, medida pelo número de viagens/dia por pessoa, relaciona-se com a facilidade com que o deslocamento pode ser realizado (Sathisan e Srinivasan, 1998). Isoladamente, o conceito de mobilidade também é carregado de indefinições, notadamente por sugerir movimento, mudança, transformação. Desse modo, o termo pode assumir inúmeras interpretações, podendo estar relacionado à mobilidade social, espacial, residencial, etc. No presente trabalho, contudo, o conceito deverá estar associado à ideia de deslocamento, relacionando-se principalmente à disponibilidade individual por modos de transporte.

Convém destacar que, conforme alertam Torquato e Santos (2004, p. 1304), "a dotação da mobilidade pode ser resolvida no plano individual, enquanto que a acessibilidade não se pode negar a pessoas e sim a coletivos". Desse modo, num contexto de pobreza, tônica dos países periféricos, a parca incidência de modos alternativos de transporte que independam de financiamento, como o próprio caminhar, além de problemas relacionados à limitada integração física e tarifária entre os diversos modos coletivos componentes dos sistemas de transporte - os quais são responsáveis pela maioria dos deslocamentos inter e intraurbanos -, resultam num processo de discriminação geográfica, uma vez que os indivíduos de menos posses têm dificultadas suas oportunidades de trabalho, estudo, consumo e lazer, justamente por não conseguirem alcançar pontos diversos da cidade pagando uma única passagem (Cardoso, 2007; Silva et al., 1994). A esse respeito, Raia Jr. (2000, p. 19) complementa que "a propensão de interação entre dois lugares cresce na medida em que o custo de movimentação entre eles diminui". Assim, equipamentos e serviços urbanos serão mais acessíveis se estiverem próximos às áreas residenciais, estando a acessibilidade potencializada também pela utilização de modos de transporte não motorizado, incluindo o andar.

Conforme aponta Villaça (1998, p. 74)

[...] a acessibilidade é o valor de uso mais importante para a terra urbana, embora toda e qualquer terra o tenha em maior ou menor grau. Os diferentes pontos do espaço urbano têm diferentes acessibilidades a todo o conjunto da cidade.

Da mesma forma, Davidson (1995) e Hanson (1995) afirmam que uma maior acessibilidade se reflete numa maior valorização da terra, uma vez que as suas condições estão relacionadas à performance do(s) sistema(s) de transporte e quantidade de oportunidades (sobretudo de trabalho) disponíveis a uma dada distância da residência de cada indivíduo (Hansen, 1959), ou seja, a sua dotação também está associada a um forte componente territorial: a localização espacial dos pontos de origem e destino dos deslocamentos. Nesse contexto, áreas mais bem equipadas em termos de infraestrutura e equipamentos urbanos (incluindo os geradores de emprego), e, por conseguinte, 
mais valorizadas economicamente, tenderão a observar melhores condições de acessibilidade em relação às demais, notadamente se houver relativa proximidade espacial entre origens e destinos. A mobilidade, por seu turno, resguarda estreitas relações com a acessibilidade, na medida em que envolve a combinação de políticas de uso e ocupação do solo, transporte e trânsito, uma vez que a geração de proximidades entre residência e postos de trabalho (além de escolas, centros de saúde e de consumo), somadas a uma boa inserção dos cidadãos perante os modos de transporte disponíveis (oferta, frequência, etc.) e a condições adequadas de circulação viária, possibilita a realização de um número maior de viagens individuais diárias e, em última análise, um melhor aproveitamento das oportunidades de "consumo" do espaço urbano.

Em Belo Horizonte, a distribuição da acessibilidade e da mobilidade espaciais tem sido recorrentemente caracterizada pela difusão de iniquidades, o que resulta na estruturação de um espaço de circulação no qual, a despeito da manutenção de privilégios ao transporte individual, os estratos mais vulneráveis (pedestres, ciclistas e usuários de transporte público coletivo) têm sido preteridos nos seus anseios relacionados à circulação. Nesse cenário, não obstante os recentes esforços de variadas esferas do Poder Público (municipal, estadual e federal) de mitigar as históricas distorções no provimento de acessibilidade, notadamente a partir da implantação do sistema de BRT (Bus Rapid Transit) em alguns dos principais corredores viários da cidade (não incluindo a sua dimensão metropolitana), importantes parcelas da população têm procurado resolvê-las individualmente.
De acordo com dados do Departamento de Trânsito de Minas Gerais (Detran-MG) e do IBGE, enquanto a população de Belo Horizon- te cresceu cerca de $18 \%$ entre 1991 e 2011, passando de 2.020.161 para 2.385.638 habi- tantes, a frota total de veículos cresceu aproximadamente $198 \%$, passando de 479.805 para 1.429 .865 veículos. Tal desequilíbrio na evolução desses dados é agravado pelo fato de que a população belo-horizontina apresentou um declínio no ritmo de crescimento ao longo das últimas décadas (em média 1,16\% ao ano, entre 1991 e 2000, e apenas 0,59\% ao ano entre 2000 e 2010), sem qualquer impacto negativo no crescimento da frota de veículos. A taxa de motorização do município (que se refere ao número total de veículos para cada mil habitantes) era de 599 veículos/1000 habitantes em 2011, valor muito próximo da cidade de São Paulo, que apresentava 618 veículos/1000 habitantes (Detran-SP), e superior a países como Japão (395), Estados Unidos (478) e Itália (539), segundo dados do International Road Traffic and Accident Database - Irtad (Irtad, 2012).

Numa observação apressada, pode-se imaginar que esse índice é plenamente favorável à cidade, tendo em conta que a taxa de motorização é consagrada como um indicador geral de desenvolvimento de cidades e países, estando comumente associada a elevações no Produto Interno Bruto (PIB) per capita (a rigor, o PIB de Belo Horizonte cresceu cerca de $37 \%$ entre 2000 e 2009, de acordo com informações do IBGE). Entretanto, tal análise não transcende o conceito tradicional de mobilidade urbana, contrapondo-se aos preceitos básicos da mobilidade urbana sustentável, que se refere à 
[...] reunião das políticas de transporte e de circulação, e integrada com a política de desenvolvimento urbano, com a finalidade de proporcionar o acesso amplo e democrático ao espaço urbano, priorizando os modos de transporte coletivo e os não motorizados, de forma segura, socialmente inclusiva e sustentável. (Brasil, 2004, p. 3)

A prevalência desse modelo, por sua vez, poderá acarretar importantes mudanças na distribuição modal do transporte na cidade. Em 2008, 54,5\% das viagens intramunicipais diárias eram realizadas por ônibus e $45,5 \%$ feitas em automóveis. Segundo dados do Plano de Mobilidade Urbana de Belo Horizonte (PlanMob-BH), ${ }^{1}$ criado pela BHTrans, como um instrumento de orientação das ações relacionadas ao transporte coletivo, ao transporte individual e ao transporte não motorizado, de modo a atender às necessidades de mobilidade da população do município, a ausência de novos investimentos na melhoria dos transportes públicos promoverá uma inversão nesse quadro em 2020 , sendo $52 \%$ das viagens realizadas por automóveis e $48 \%$ pelo transporte coletivo (BHTrans, 2010). Além disso, o avanço da motorização tem contribuído para a manutenção de baixas velocidades médias do transporte coletivo (modo ônibus) na capital mineira, que, em 2008, era de 19,8 km/h na rede viária municipal e 14,3 $\mathrm{km} / \mathrm{h}$ na área central nos horários de pico. Situação semelhante, resguardadas as devidas proporções, era vivenciada pelos usuários de automóveis, cujos veículos apresentavam velocidade média de $26,2 \mathrm{~km} / \mathrm{h}$ no sistema viário municipal e $18 \mathrm{~km} / \mathrm{h}$ no centro no mesmo período (BHTrans, 2010).
A análise das condições de mobilidade e acessibilidade espaciais na RMBH, através de indicadores específicos, como proposto neste trabalho, permite a construção de um diagnóstico que supera o simples (re)conhecimento de uma condição dada. Os resultados obtidos com base nos deslocamentos e suas respectivas relações com os indicadores distância, tempo e velocidade permitem o reconhecimento de padrões distribuídos em nível local, poderão subsidiar, em trabalhos futuros, a formulação de medidas propositivas que visem minimizar eventuais distorções na distribuição e no provimento da mobilidade e da acessibilidade metropolitanas.

\section{Base de dados e a operacionalização metodológica}

Historicamente os censos demográficos têm se consolidado como uma das mais importantes bases de dados utilizadas nas diversas vertentes das ciências humanas e sociais. 0 primeiro recenseamento foi realizado no Brasil em 1872, quando ocorreu a primeira grande contagem da população. Até a primeira metade do século XX, foram realizados os censos de 1890, 1900, 1920 e 1940. No entanto, o Brasil adotou os padrões internacionais apenas a partir de 1940, quando o recém-criado IBGE assumiu a tarefa de planejamento, execução e divulgação do censo demográfico. Inaugura-se, assim, uma fase de modernização dos censos no Brasil, que passaram a exibir uma periodicidade decenal (regularidade quebrada pelo Censo de 1991). ${ }^{2}$ 
A partir de então, ampliou-se a temática com a introdução dos quesitos de interesse econômico e social nos questionários censitários. Desde então, são coletadas nos censos informações referentes às características dos domicílios e moradores, o que permite determinar o perfil demográfico e socioeconômico da população do país, bem como realizar estimativas, estudos e diagnósticos com o objetivo de subsidiar o planejamento e o desenvolvimento de políticas e programas governamentais

Os dados que compreendem as caracte rísticas dos domicílios e das pessoas que foram investigadas para a totalidade da população são denominados, por convenção, resultados do universo. Esses dados foram obtidos reu- nindo informações captadas por meio da in- vestigação das características dos domicílios e das pessoas, que são comuns aos dois tipos de questionários utilizados para o levantamento do censo demográfico de 2010. Nele, como descrito na própria documentação disponibilizada pelo IBGE, foram utilizados dois tipos de questionário, que são: (1) questionário básico - aplicado em todas as unidades domiciliares, exceto naquelas selecionadas para a amostra, e que contém a investigação das características do domicílio e dos moradores; e (2) questionário da amostra - aplicado em todas as unidades domiciliares selecionadas para a amostra. Além da investigação contida no questionário básico, abrange outras características do domicílio e pesquisa importantes informações sociais, econômicas e demográficas dos seus moradores.

Neste artigo, em função dos propósitos estabelecidos inicialmente, optou-se em analisar os deslocamentos a partir das unidades espaciais denominadas Areaps, que são definidas como sendo uma unidade geográfica, formada por um agrupamento de setores censitários, para a aplicação dos procedimentos de calibração das estimativas com as informações conhecidas para a população como um todo. Foram definidas, para todo o Brasil, 10.184 Areaps e, tal como nos censos anteriores, a me- todologia de expansão da amostra foi aplicada independentemente para cada uma delas. Além do limite quanto ao tamanho mínimo razoável, essas áreas também consideraram os níveis geográficos mais detalhados da base operacio- nal, como forma de atender a demandas por in- formações em níveis geográficos menores que os municípios.

Para o Censo 2010, de acordo com o próprio IBGE, foram usados métodos e sistemas automáticos de formação de Areaps que conjugam critérios tais como tamanho (para permitir estimativas com qualidade estatística em áreas pequenas), contiguidade (no sentido de serem constituídas por conjuntos de setores limítrofes com algum sentido geográfico) e homogeneidade em relação a um conjunto de características populacionais e de infraestrutura conhecidas. A fração amostral dos domicílios no Censo de 2010 variou conforme o tamanho da população residente em cada município. As proporções foram obtidas de acordo com as seguintes classes: (1) até 2.500: $50 \%$ dos domicílios; (2) superior a 2.500 até 8.000 : $33 \%$ dos domicílios; (3) superior a 8.000 até 20.000 : $20 \%$ dos domicílios; (4) superior a 20.000 até 500.000: 10\% dos domicílios; e (5) superior a 500.000: 5\% dos domicílios. Para os 40 municípios com mais de 500.000 habitantes, foi avaliada a possibilidade de aplicação de frações amostrais diferentes em cada uma de suas divisões administrativas intramunicipais (distritos e 
subdistritos), de forma a permitir a divulgação de estimativas e de microdados nesses níveis geográficos. Em todo o território nacional foram selecionados 6.192.332 domicílios para responder ao questionário da amostra, o que significou uma fração amostral efetiva da ordem de 10,7\% para o país.

Uma das importantes inovações trazidas na atual edição refere-se à inclusão de variáveis adicionais no quesito referente ao chamado movimento pendular, o que permitiu a distinção da motivação principal daqueles que trabalhavam ou estudavam em um município diferente daquele de residência na data de referência do levantamento censitário. ${ }^{3}$ Para a pessoa com mais de 10 anos de idade, que trabalhava fora do domicílio e retornava diariamente, exceto para aquele que trabalhava em mais de um município ou país, foi pesquisado o tempo habitual gasto de deslocamento do domicílio até o trabalho principal. Os intervalos de tempo de deslocamento do domicílio para o trabalho principal foram classificados em: até cinco minutos, de seis minutos até meia hora, mais de meia hora até uma hora, mais de uma hora até duas horas, ou mais de duas horas. Com base nesse agrupamento, considerados os valores centrais de cada classe, foi possível estimar o tempo médio gasto no deslocamento diário daqueles que declararam residir nas Areaps pertencentes aos municípios da periferia que declararam trabalhar no centro metropolitano.

A estimativa da distância, em função das limitações inerentes às informações disponíveis na base de dados censitária, foi obtida tendo como referência os centróides relativos aos polígonos que representam as Areaps e os municípios centrais de cada região metropolitana, processados com base em Sistemas Geográficos de Informação (SIGs). Ainda que sejam apenas escores aproximados, que necessariamente subestimam a distância real percorrida, uma vez que definem a distância linear entre dois pontos (distância euclidiana), permitem aferir os efeitos da proximidade ou não ao considerar o tempo de cada deslocamento. Dessa forma, também é possível estimar a velocidade pela razão entre os valores de distância e tempo, tendo, portanto, um importante indicador de acessibilidade e mobilidade espacial da população no interior das regiões metropolitanas e de suas regiões integradas de desenvolvimento.

\section{Análise das condições de acessibilidade e mobilidade espaciais intermunicipais na RMBH: algumas evidências empíricas}

Antes de considerar os indicadores de acessibilidade e a mobilidade intermunicipais metropolitanas, apoiadas em uma análise comparativa dessas condições nas nove principais Regiões Metropolitanas (RMs) nacionais e as suas respectivas Regiões Integradas de Desenvolvimento (Rides), conforme a subdivisão territorial adotada no censo demográfico de 2010, ${ }^{4}$ convém realizar uma breve análise do grau de centralidade das regiões em questão. Para tanto, serão comparados dados sobre a proporção dos trabalhadores residentes nos municípios das periferias metropolitanas, os quais realizam 
movimentos pendulares diários com destino aos núcleos metropolitanos, e aqueles que declararam trabalhar no próprio município de residência. As RMs estudadas são apresentadas na Figura 1.

Um dado que desperta imediata atenção é o significativo número de respondentes que declarou trabalhar no mesmo município de residência em todas as regiões metropolitanas analisadas. Excetuando as regiões do Rio de Janeiro e do Recife, que apresentaram, respectivamente, $59,88 \%$ e $57,99 \%$ de trabaIhadores nessas condições, todas as demais experimentaram percentuais superiores a $62 \%$ (com destaque para Salvador e Fortaleza, com índices acima de 70\%). Esse fenômeno pode estar relacionado às expressivas mudanças que marcaram a reversão na tendência de crescimento populacional dos núcleos metropolitanos (e, alguns casos, das próprias regiões metropolitanas), os quais tiveram início na década de 1970, que, até então, apresentava um padrão predominantemente centralizador. 0 arrefecimento do crescimento populacional dos núcleos metropolitanos é resultado, entre outros aspectos, do avanço das chamadas deseconomias de aglomeração, que incluem fatores sociais, como o aumento da criminalidade urbana, e refletem incrementos pela elevação dos custos de moradia e trabaIho (Redwood, 1984).

No caso belo-horizontino, centro das in- vestigações deste trabalho, a partir dos anos de 1970, como já demonstraram Rigotti e Rodrigues (1994), Matos (1995) e Rigotti (1999), dentre outros, era perceptível uma desaceleração no ritmo de crescimento da capital mineira. A partir desse momento, os municípios da periferia da RMBH vêm apresentando incrementos populacionais bem mais significativos do que Belo Horizonte, os quais experimentaram taxas de crescimento populacional anual da ordem de $6,84 \%, 5,01 \%$ e $4,40 \%$ entre os períodos de 1970/1980, 1980/1991 e 1991/2000, respectivamente. Nesses mesmos períodos, o município de Belo Horizonte apresentou taxas anuais de 3,73\%, 1,15\% e 1,10\%. Esses diferenciais no ritmo de crescimento da periferia metropolitana tiveram reflexo na evolução da participação do core metropolitano nos estoques totais de população na região. Desde 1970, a periferia metropolitana vem crescendo em volume e na proporção da população regional. Em 2000, 48,63\% da população da região metropolitana residia fora de Belo Horizonte (em 1970 essa proporção era de apenas 33,59\%), conforme apontam Lobo, Cardoso e Matos (2008).

Percebe-se, por outro lado, a elevada polarização dos núcleos das Regiões Metropolitanas de Belém, Curitiba, Recife e Rio de Janeiro, com uma atratividade superior a $25 \%$ de trabalhadores metropolitanos que residem fora dessas capitais.

0 caso do Rio de Janeiro merece atenção especial, já que, não obstante a grande atratividade da capital fluminense, cerca de $15 \%$ dos trabalhadores residentes nessa região declararam trabalhar em um município metropolitano diferente do núcleo e do próprio município de residência. Tal fato pode ser explicado por um relativo dinamismo econômico de outros municípios integrantes da Região Metropolitana do Rio de Janeiro, a exemplo de Niterói, que, por prefigurar-se como um dos principais centros financeiros, comerciais e industriais do Estado, pode exercer certa atratividade de trabalhadores de outras cidades metropolitanas. 
Figura 1 - Proporção da população dos municípios da periferia que declarou trabalhar no próprio município de residência e no respectivo núcleo metropolitano - Regiões Metropolitanas

e Regiões Integradas de Desenvolvimento - Brasil (2010)

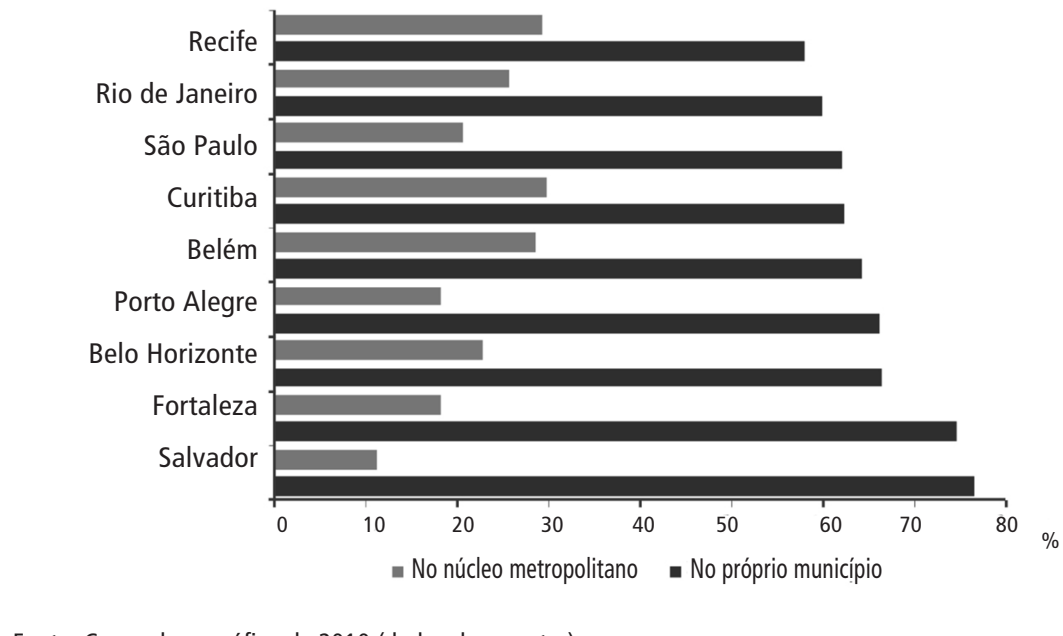

Fonte: Censo demográfico de 2010 (dados da amostra).

Exercendo uma centralidade menor, mas não menos significativa, encontram-se as regiões de Belo Horizonte, São Paulo, Fortaleza e Porto Alegre, cujos núcleos atraem, em média, cerca de $20 \%$ da mão de obra residente nas periferias. A Região Metropolitana de Porto Alegre, da mesma forma que a do Rio de Janeiro, apresenta aproximadamente $16 \%$ de trabaIhadores residentes em municípios da periferia que realizam movimentos pendulares diários para outras cidades metropolitanas que não as de origem e o core. Nesse caso, municípios como Canoas, que detém indústrias e centros de ensino superior, e Triunfo, que abriga um importante polo petroquímico, podem responder por atrair parte da mão de obra metropolitana.
A Região Metropolitana de Salvador, por sua vez, apresenta dados que destoam bastante das demais regiões, uma vez que a capital é destino de cerca de $11 \%$ dos trabalhadores. Outros $76 \%$ trabalham no município de origem e cerca de $13 \%$ em outras cidades que integram a respectiva região. É possível que o município de Camaçari responda por parte dessa atratividade de trabalhadores, notadamente por abrigar um importante complexo industrial químico, petroquímico e automotivo (embora essas informações não tenham sido alvo de tabulação neste trabalho, assim como algumas ponderações feitas sobre as regiões do Rio de Janeiro e de Porto Alegre, tendo em conta os seus objetivos principais). 
No tocante à mobilidade, em princípio, 0 alto número de deslocamentos direcionados aos núcleos, incluindo Belo Horizonte (que recebia, em 2010, 22,82\% dos trabalhadores - 332.314 - da periferia metropolitana), poderia sugerir que as populações das respectivas regiões metropolitanas apresentam elevados níveis a esse indicador. Se considerada a mobilidade relativamente aos deslocamentos intermunicipais, esta análise é verdadeira, uma vez que as regiões que apresentam núcleos metropolitanos mais atrativos gerariam um grande número de viagens e, por conseguinte, perceberiam melhores condições de mobilidade. Contudo, conforme citado, a mobilidade é tradicionalmente mensurada pelo número de viagens individuais diárias. Como os dados do Censo 2010 não permitem a investigação desses dados, pode-se inferir, empiricamente, que seja provável que os índices de mobilidade nessas regiões não sejam tão elevados, já que se tratam de movimentos pendulares (que tendem a envolver maiores distâncias), fato que limita a ocorrência de um maior número de deslocamentos individuais (inclusive intramunicipais), para a realização de outras atividades além das laborais.

Quanto à acessibilidade, a partir das informações apresentadas na Tabela 1, as regiões de Belém, Recife e Belo Horizonte apresentam as menores velocidades médias de deslocamento direcionado aos seus núcleos $(16,29$ $\mathrm{km} / \mathrm{h}, 16,43 \mathrm{~km} / \mathrm{h}$, e $19,39 \mathrm{~km} / \mathrm{h}$ ) comparativamente às demais, que apresentaram velocidades médias superiores a $20 \mathrm{~km} / \mathrm{h}$. Merecem destaque as Regiões Metropolitanas do Rio de Janeiro e São Paulo, que apresentaram maior eficiência em termos de acessibilidade, com velocidades médias superiores a $25 \mathrm{~km} / \mathrm{h}$, ainda que experimentassem os maiores tempos de viagem (1,57 h e 1,36 h, respectivamente). Os elevados tempos de viagem, no entanto, podem ser justificados pelas maiores distâncias médias de deslocamento nestas regiões (Rio de Janeiro: 31,12 km; São Paulo: 26,79 km).

Belo Horizonte, por sua vez, apresentou um dos piores índices de eficiência, com o terceiro pior tempo de viagem $(1,13 \mathrm{~h})$, mesmo apresentando a quarta menor distância média entre origem e destino $(17,63 \mathrm{~km})$. Tais resultados podem ser compreendidos, em parte, pela inexistência de modalidades de transporte sobre trilhos com abrangência verdadeiramente metropolitana (diferentemente dos casos do Rio de Janeiro e de São Paulo). Cabe ressaltar que o Trem Metropolitano de Belo Horizonte caracteriza-se por possuir tecnologia de metrô (de superfície) e, em termos "potenciais", atender a parte da RMBH. Todavia, apresenta uma limitada abrangência espacial, essencialmente local, possuindo um único ramal (denominado Linha 1), que conta com 28,1 km de extensão, ligando a Regional Venda Nova (Estação Vilarinho) até o município de Contagem (Estação Eldorado). Noutros termos, estabelece conexão entre a porção norte de Belo Horizonte, margeando a área central, com parte de (reduzida) porção oeste da $\mathrm{RMBH}$, deixando desassistidos outros 32 municípios metropolitanos. Segundo informações da Companhia Brasileira de Trens Urbanos (CBTU), empresa federal que gerencia o sistema, as viagens têm, atualmente, a duração média de 44,7 minutos entre as estações Vilarinho e Eldorado (CBTU, 2013). Considerando essa relação entre distância percorrida e tempo de viagem realizada pelo Trem Metropolitano, a sua (necessária) ampliação poderia contribuir para a melhoria dos indicadores de acessibilidade da $\mathrm{RMBH}^{5}$ 
Tabela 1 - Média de distância, tempo e velocidade dos deslocamentos da população residente nos municípios da periferia que declarou trabalhar no respectivo núcleo metropolitano - Regiões Metropolitanas

e Regiões Integradas de Desenvolvimento - Brasil (2010)

\begin{tabular}{l|c|c|c}
\hline \multirow{2}{*}{$\begin{array}{c}\text { Região Metropolitana } \\
\text { (municípios da periferia) }\end{array}$} & \multicolumn{3}{|c}{ Acessibilidade } \\
\cline { 2 - 4 } & Distância (em km) & Tempo (em horas) & Velocidade (km/h) \\
\hline Belém & 13,63 & 1,07 & 16,29 \\
Belo Horizonte & 17,63 & 1,13 & 19,39 \\
Curitiba & 20,14 & 0,99 & 27,13 \\
Fortaleza & 17,11 & 0,93 & 22,96 \\
Porto Alegre & 19,5 & 1,00 & 24,33 \\
Recife & 12,75 & 1,01 & 16,43 \\
Rio de Janeiro & 31,12 & 1,57 & 25,22 \\
Salvador & 20,95 & 1,09 & 25,04 \\
São Paulo & 26,79 & 1,36 & 26,15 \\
\hline
\end{tabular}

Fonte: Censo Demográfico de 2010 (dados da amostra).

Ao analisar a acessibilidade para 0 ca- so da RMBH, com base nos valores de representados na Figura 2, percebe-se que 0 maior número de deslocamentos com destino a Belo Horizonte, em termos absolutos, tem origem em municípios mais próximos da $\mathrm{Ca}$ pital (a chamada periferia imediata), que encerram maior facilidade (potencial) de acesso em função dessa proximidade espacial e do avanço de processos de conurbação. Merece menção os deslocamentos originados nas Areaps localizadas em porções dos municípios do eixo norte da RMBH (Vespasiano, Ribeirão das Neves e Santa Luzia), dos vetores oeste e sudoeste (Contagem, Betim e Ibirité), do vetor leste (Sabará) e do eixo sul (Nova Lima). Em cada uma delas detectou-se um número de deslocamentos destinados a Belo Horizonte superior a 5.000. Na mesma Figura 2, considerados os parâmetros que apresenta a proporção que os fluxos para o core representam em relação à população que declarou trabalhar, os resultados se revelam um pouco distintos. Com comportamento semelhante ao observado nos resultados absolutos, os eixos norte, leste e sudoeste da RMBH afiguram-se como os que apresentam maiores índices proporcionais de movimentos pendulares com destino à Capital mineira. Tratam-se de áreas que, historicamente, apresentam elevada dependência econômica de Belo Horizonte, prefigurando-se como "cidades dormitório", a exemplo de Ribeirão das Neves, Santa Luzia, Ibirité e Sabará. 
Outros municípios, como Nova Lima, Contagem e Betim, revelaram baixos índices de movimentos pendulares (proporcionalmente à população trabalhadora) com destino ao núcleo. Esses resultados atestam que, ainda que Belo Horizonte tenha mantido sua centralidade ao longo das últimas décadas, há um ganho de autonomia de um número razoável de municípios na região. Conforme já descrito por Lobo, Cardoso e Matos (2008), vários municípios antes apresentados como meras cidades-dormitórios nas décadas de 1960 e 1970, além de ampliar suas inter-relações com o core, apresentam forte desenvolvimento de determinadas funcionalidades eminentemente urbanas, o que tem permitido que uma crescente parcela da população local tenha suas atividades econômicas/profissionais desenvolvidas no próprio município de residência, 0 que tem diminuído a proporção e/ou o volume daqueles que fazem movimentos diários entre a periferia e núcleo metropolitano.

A Figura 3, que apresenta dados sobre 0 tempo médio e a velocidade dos deslocamentos de trabalhadores para Belo Horizonte, mostra que, à exceção da cidade de Sete Lagoas (vetor noroeste), os tempos de viagem mais elevados têm origem em Areaps mais distantes do core metropolitano (Figura 2). Esse é um resultado esperado, considerando que deslocamentos mais longos tendem a apresentar tempos maiores de viagem, sobretudo no contexto da RMBH, que, como alertado anteriormente, não dispõe, com abrangência metropolitana, de modos de transporte coletivo dotados de maior eficiência, como o metrô. Quanto à situação de Sete Lagoas, que pertence à Ride, esta pode ser explicada em razão do acesso à Belo Horizonte ser realizado, eminentemente, por uma rodovia federal (BR-040), a qual, pelas suas características de ligação regional e, consequentemente, de priorização do tráfego de passagem (atravessamento), viabiliza uma maior fluidez viária, comparativamente às redes viárias intraurbanas.

Ainda em relação ao indicador tempo, algumas Areaps pertencentes a municípios conurbados a Belo Horizonte, diferentemente da média observada, apresentaram tempos médios relativamente elevados (superiores a uma hora). É caso de frações dos municípios de Ibirité (sudoeste) e Santa Luzia (norte), os quais, não obstante o fato de fornecerem importantes contingentes de mão de obra para o core (o que gera maior pressão sobre os seus sistemas viário e de transporte), têm acesso dificultado a ele em função dos elevados índices de saturação do tráfego nas respectivas vias de conexão com Belo Horizonte (os chamados gargalos). No vetor sudoeste 0 acesso é realizado pela Avenida Amazonas, que, além de interligar a Capital a grande parte do vetor oeste, em especial, Contagem e Betim (que abrigam o principal complexo industrial do Estado), tem como agravante a confluência com o Anel Rodoviário (construído, na década de 1960, para retirar o tráfego de caminhões das áreas centrais do município e que atualmente recebe também tráfego de características eminentemente urbanas). No vetor norte a ligação é realizada pela Avenida Cristiano Machado, que integra a recém-inaugurada Linha Verde, configurando-se como o principal corredor de ligação não somente com os municípios desse vetor, mas, principalmente, a importantes equipamentos e serviços, como a Cidade Administrativa (sede do Governo de Minas Gerais), localizada 
no município de Vespasiano, e o Aeroporto Internacional Tancredo Neves, situado no município de Confins.

Em relação à velocidade média dos des- locamentos (Figura 3), as Areaps integrantes de municípios conurbados a Belo Horizonte apresentaram menores velocidades (inferiores a $20 \mathrm{~km} / \mathrm{h}$ ) em comparação às mais distantes do núcleo. Tal resultado pode ser compreendido em razão das características de tráfego das principais vias de acesso à Capital, as quais, já a partir do perímetro da cidade, tendem a reproduzir compor tamentos típicos de vias intraurbanas, em geral, reféns de congestionamentos viários, principalmente nos horários de pico, períodos em que é realizada a maior parte das viagens motivadas pelo trabalho. Por seu turno, os trabalhadores que realizam deslocamentos mais longos rumo ao core metropolitano também enfrentam os mesmos problemas, porém, em grande medida, nas proximidades do perímetro de Belo Horizonte, o que contribui para que as velocidades médias percebidas sejam relativamente maiores, considerando que parte da viagem acontece em melhores condições de fluidez viária (tanto para usuários do transporte público quanto do transporte individual). 
Figura 2 - Número e percentual de deslocamentos diários da população dos municípios da periferia que declarou trabalhar em Belo Horizonte (2010)
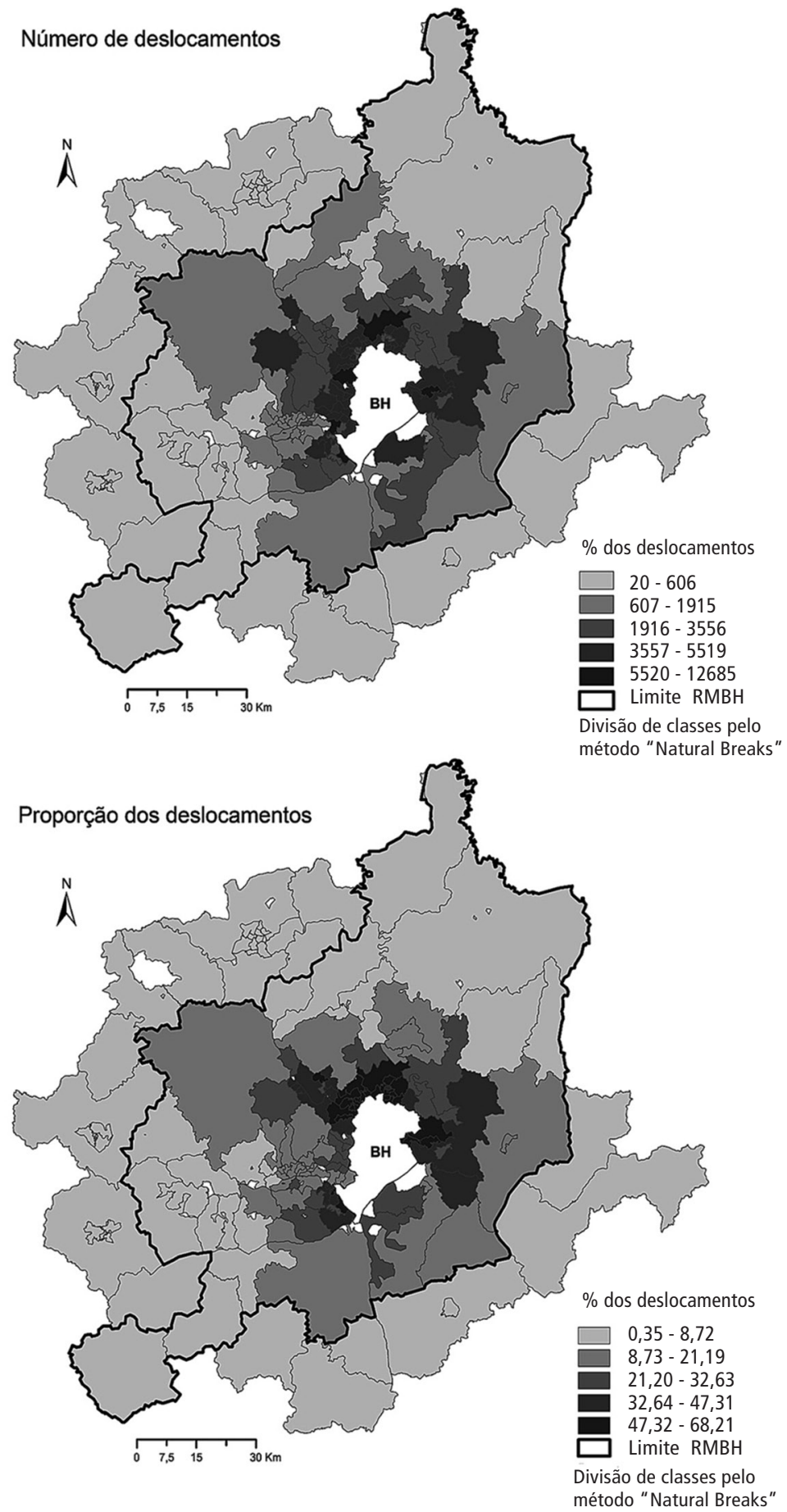

Fonte: Censo demográfico de 2010 (dados da amostra) 
Figura 3 - Média de tempo e velocidade dos deslocamentos da população residente nos municípios da periferia que declarou trabalhar em Belo Horizonte, 2010
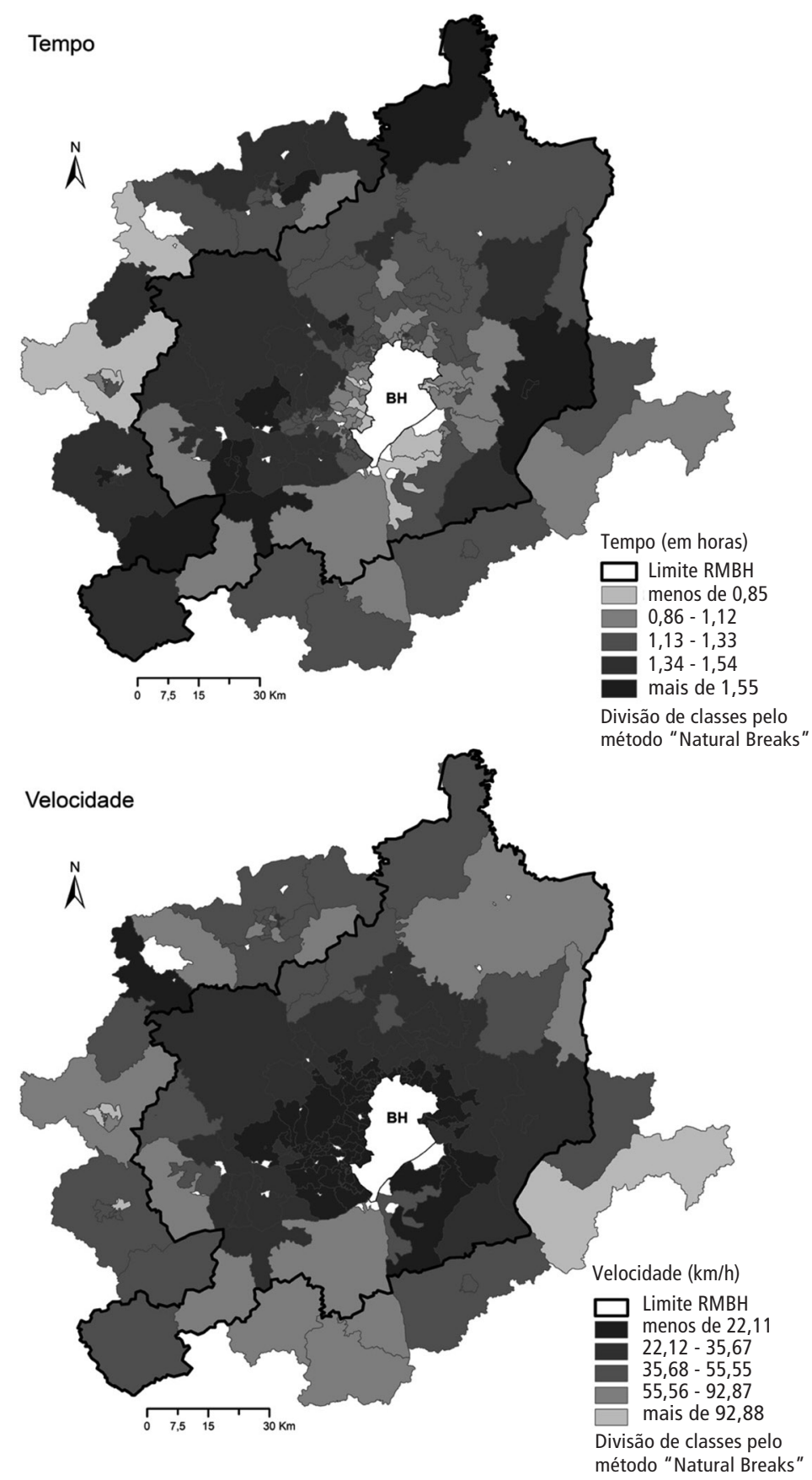

Fonte: Censo demográfico de 2010 (dados da amostra) 


\section{Considerações finais}

Na Região Metropolitana de Belo Horizonte (RMBH), assim como em diversas outras metrópoles brasileiras, verifica-se a reprodução de precariedades na provisão de acessibilidade e mobilidade espaciais, reflexo da (in)capacidade de intervenção do Poder Público diante do processo de urbanização e dos círculos viciosos que perpassam os processos de inclusão social e desenvolvimento econômico e social. Nesse contexto, o incremento da motorização individual trouxe vários prejuízos às condições de deslocamento da população, em escala intra e intermunicipal, uma vez que direta e indiretamente refletem na baixa eficiência do transporte coletivo, sobretudo nas áreas de maior aglomeração de serviços e demais atividades geradoras de emprego.

A partir das análises realizadas neste trabalho, balizadas em informações do Censo De- mográfico de 2010, observou-se que a RMBH apresentou índices de acessibilidade (relação entre distância, tempo de viagem e velocida- de média) inferiores aos experimentados pela maioria das regiões metropolitanas nacionais estudadas. As análises espaciais, que permitiram avaliar as condições gerais de acessibilidade na RMBH, também mostraram que, salvo exceções, os municípios mais próximos do core metropolitano contribuem com contingentes mais significativos de trabalhadores (absolutos e percentuais) com a composição da mão de obra belo-horizontina, resultado da proximidade espacial e, em alguns casos, da manutenção da condição de dependência econômica da Capital. Além disso, constatou-se também que, apesar dos tempos de viagem com origem em municípios conurbados a Belo Horizonte serem relativamente menores em comparação às cidades mais distantes, a velocidade média dos deslocamentos mais longos tende a ser maior do que velocidades das viagens mais próximas. Os alardeados gargalos no trânsito da cidade, sobretudos nas principais vias de acesso à Capital, já nas proximidades do seu perímetro é uma das causas explicativas para tal comportamento.

Ainda que os dados censitários não ofe- reçam informações específicas sobre 0 modo de transporte utilizado e não registrem o tempo gasto nos deslocamentos diários da população laboral (são declarados apenas dados categorizados), sua abrangência, ao compreender um amplo leque variáveis socioeconômicas, bem como a considerável representatividade de sua base amostral, permite análises consistentes e detalhadas sobre a mobilidade espacial da população. As novas edições do censo brasileiro, caso mantenha e/ou amplie o rol de variáveis sobre esse tipo deslocamento espacial da população, podem oferecer inúmeras possibilidades às análises sobre a mobilidade e a acessibilidade, tanto no âmbito metropolitano, como nos demais núcleos urbanos do país. 


\section{Carlos Lobo}

Universidade Federal de Minas Gerais, Departamento de Geografia, Instituto de Geociências. Belo Horizonte/MG, Brasil.

cfflobo@yahoo.com.br

\section{Leandro Cardoso}

Universidade Federal de Minas Gerais, Departamento de Engenharia de Transportes e Geotecnia. Belo Horizonte/MG, Brasil.

leandrocardoso@hotmail.com

\section{David J. A. V. Magalhães}

Universidade Federal de Minas Gerais, Professor do Departamento de Engenharia de Transportes e Geotecnia. Belo Horizonte/MG, Brasil.

david@etg.ufmg.br

\section{Notas}

(1) As caracterizações mais gerais sobre a acessibilidade e a mobilidade urbanas foram centradas essencialmente em Belo Horizonte em função da carência de informações mais detalhadas sobre a RMBH, cujos dados mais recentes datam de 2002, ano da publicação da última Pesquisa Domiciliar de Origem e Destino na RMBH (Pesquisa OD). Comumente realizada decenalmente e com o objetivo de produzir informações básicas necessárias para o planejamento e gestão do transporte e do tráfego metropolitanos, a pesquisa OD, realizada no final de 2012, tem sua divulgação prevista para meados do primeiro semestre de 2013. Desse modo, análises mais consistentes, não contempladas pelos dados produzidos pelo Censo Demográfico de 2010, poderão então ser realizadas para a RMBH. No Censo 2010 foram incorporadas, pela primeira vez, questões sobre mobilidade e acessibilidade, porém limitadas à identificação do município, unidade da federação ou país estrangeiro de trabalho do respondente; se o respondente retorna para a sua residência diariamente; e qual é o tempo habitual de deslocamento entre casa e trabalho.

(2) O primeiro regulamento censitário no Brasil data de 1846, quando foi definida a periodicidade de oito anos para os censos demográficos. No entanto, somente em 1850 o governo foi autorizado a despender os recursos necessários para a realização de uma operação do porte de um censo demográfico. O primeiro censo, então, foi programado para ocorrer em 1852. Entretanto, a operação prevista para esse ano não foi realizada. Em 1870, um novo regulamento censitário determinou que os Censos cobrissem todo o território nacional e que deveriam ocorrer a cada dez anos. Dois anos mais tarde, em 1872, foi realizado o primeiro recenseamento nacional no país, o qual recebeu o nome de Recenseamento da População do Império do Brasil. Novas operações censitárias se sucederam em 1890, 1900 e 1920 até 1940. Com a criação do IBGE, em 1936, inaugurou-se a moderna fase censitária no Brasil, cujo marco foi a divulgação do Censo Demográfico de 1940. Caracterizada, principalmente, pela periodicidade decenal, nessa nova fase foi ampliada a abrangência temática do questionário com introdução de quesitos de interesse econômico e social, tais como: mão de obra, emprego, desemprego, rendimento, fecundidade, migrações internas, entre outros temas. 
(3) A investigação de trabalho e rendimento abrangeu as pessoas de 10 anos ou mais de idade e considerou como trabalho em atividade econômica o exercício de ocupação: 1) remunerada em dinheiro, produtos, mercadorias ou benefícios (moradia, alimentação, roupas, treinamento, etc.) na produção de bens ou serviços; 2) remunerada em dinheiro ou benefícios (moradia, alimentação, roupas, treinamento, etc.) no serviço doméstico; 3) sem remuneração na produção de bens e serviços, desenvolvida em ajuda na atividade econômica, no setor privado, de morador do domicílio; ou 4) desenvolvida na produção de bens, compreendendo as atividades da agricultura, pecuária, caça, produção florestal, pesca e aquicultura, destinados somente à alimentação de, pelo menos, um morador do domicílio.

(4) As regiões metropolitanas constituem um agrupamento de municípios com a finalidade de executar funções públicas que, por sua natureza, exigem a cooperação entre esses municípios para a solução de problemas comuns, como os serviços de saneamento básico e de transporte coletivo, o que legitima, em termos político-institucionais, sua existência, além de permitir uma atuação mais integrada do poder público no atendimento às necessidades da população ali residente, identificada com o recorte territorial institucionalizado. A criação de Regiões Integradas de Desenvolvimento está prevista na Constituição Federal de 1988, nos Art. 21, inciso IX; Art. 43; e Art. 48, inciso IV. São conjuntos de municípios cuja origem se baseia no princípio de cooperação entre os diferentes níveis de governo - federal, estadual e municipal. Podem ser compostas por municípios de diferentes unidades federadas. Nas análises do presente artigo, embora sejam também contempladas informações sobre as Rides, com o intuito de evitar equívocos na compreensão das ponderações, serão feitas menções tão somente às regiões metropolitanas, por ser esta uma denominação consagrada na literatura.

(5) Análises mais aprofundadas seriam possíveis se o Censo 2010 elencasse informações sobre os modos de transporte utilizados pelos respondentes nos seus deslocamentos diários. Mesmo diante dessa impossibilidade, os dados auferidos de velocidade média dos deslocamentos para Belo Horizonte auxiliam na convalidação do uso do censo demográfico para a realização de análises de acessibilidade e mobilidade urbanas. Nesse sentido, a velocidade média de 19,39 km apresentada para Belo Horizonte está alinhada às velocidades médias mostradas pelo PlanMob-BH para o ano de 2008. No mencionado Plano de Mobilidade, a velocidade média combinada das viagens de ônibus e automóveis era de $23 \mathrm{~km} / \mathrm{h}$ na rede viária municipal e de $16,1 \mathrm{~km} / \mathrm{h}$ na área central do município.

\section{Referências}

BRASIL (2004). Política Nacional de Mobilidade Urbana Sustentável. Brasília, Secretaria Nacional de Transporte e Mobilidade Urbana, Ministério das Cidades.

CARDOSO, L. (2007). Transporte público, acessibilidade urbana e desigualdades socioespaciais na Região Metropolitana de Belo Horizonte. Tese de doutorado. Belo Horizonte, Universidade Federal de Minas Gerais.

COMPANHIA BRASILEIRA DE TRENS URBANOS - CBTU (2013). Metrô BH. Disponível em: http://www. cbtu.gov.br/operadoras/sites/menuprincbh.htm. Acesso em: 2 fev 2013. 
DAVIDSON, K. B. (1995). Accessibility and isolation in transportation network evaluation. Paper presented at 7th WORLD CONFERENCE ON TRANSPORT RESEARCH. The University of New South Wales, Sydney, Australia.

EMPRESA DE TRANSPORTES E TRÂNSITO DE BELO HORIZONTE - BHTRANS (2010). Plano de Mobilidade Urbana de Belo Horizonte - Relatório Final. Belo Horizonte.

HANSEN, W. G. (1959). How accessibility shapes land use. Journal of the American Institute of Planners, v. 25, n. 2 , pp. $73-76$.

HANSON, S. (1995). "Getting there: urban transportation in context". In: HANSON, S. (ed.) The geography of urban transportation. New York/London, The Guilford Press.

HICKS, J. (1979). "Centros comerciais e descentralização metropolitana: exame do caso de Belo Horizonte". In: BARAT, J. Política de desenvolvimento urbano: aspectos metropolitanos e locais. Rio de Janeiro, IPEA/INPES.

IRTAD (2012). International Traffic Safety Data and Analysis Group. Disponível em: http:// internationaltransportforum.org/irtadpublic/index.html. Acesso em: 18 nov 2012.

JONES, S. R. (1981). Accessibility measures: a literature review. Transport and Road Research Laboratory. Laboratory Report 967.

LOBO, C.; CARDOSO, L. e MATOS, R. (2008). Mobilidade pendular e centralidade econômica na Região Metropolitana de Belo Horizonte. In: XVI ENCONTRO NACIONAL DE ESTUDOS POPULACIONAIS. Anais. Caxambu, v. 1.

(2010). Transporte coletivo em Belo Horizonte: a eficiência de acessibilidade com base na Pesquisa Domiciliar Origem e Destino de 2002. In: 40 CONGRESSO LUSO-BRASILEIRO PARA O PLANEJAMENTO URBANO, REGIONAL, INTEGRADO E SUSTENTÁVEL. Anais. Faro (Portugal).

MATOS, R. (1995). Dinâmica migratória e desconcentração da população na macrorregião de Belo Horizonte. Tese de doutorado. Belo Horizonte, Universidade Federal de Minas Gerais.

RAIA JR., A. A. (2000). Acessibilidade e mobilidade na estimativa de um índice de potencial de viagens utilizando redes neurais artificiais e sistemas de informação. Tese de doutorado. São Carlos, Universidade de São Paulo.

REDWOOD III, J. (1984). Reversion de polarizacion, ciudades secundarias y eficiencia en el desarrollo nacional: una vison teorica aplicada al Brasil contemporaneo. Revista Latinoamericana de Estudios Urbanos Regionales. Santiago, v. 11, n. 32.

RIGOTTI, J. I. R. (1999). Técnicas de mensuração das migrações a partir de dados censitários: aplicação aos casos de Minas Gerais e São Paulo. Tese de doutorado. Belo Horizonte, Universidade Federal de Minas Gerais.

RIGOTTI, J. I. R. e RODRIGUE S, J. N. (1994). Distribuição espacial da população na região Metropolitana de Belo Horizonte. In: IX ENCONTRO DE ESTUDOS POPULACIONAIS. Anais. Caxambu, v. 1, pp. 435-456.

SATHISAN, S. K.; SRINIVASAN, N. (1998). Evaluation of accessibility of urban transportation networks. Transportation Research Record, n. 1617, p. 78-83

SILVA, A. N. R. et al. (1994). Integração tarifária no transporte por ônibus: com ou sem terminal? Revista dos Transportes Públicos - ANTP. São Paulo, ano 16, n. 63, pp. 30-38. 
TORQUATO, A. M. S. C. e SANTOS, E. (2004). Políticas de transporte e pobreza urbana: reflexões e evidências em um bairro periférico de Natal. In: CONGRESSO DE PESQUISA E ENSINO EM TRANSPORTES - ANPET. Anais. Florianópolis, UFSC, pp. 1300-1311.

VILLAÇA, F. (1998). Espaço intra-urbano no Brasil. São Paulo, Lincoln Institute/Fapesp/Studio Nobel.

Texto recebido em 12/mar/2013

Texto aprovado em 5/maio/2013 
